\title{
Myopia: A School Eye Survey in Rural and Urban Area of Faridabad, Haryana
}

\author{
Deepak Gupta ${ }^{1}$, Raj Kumar ${ }^{2}$, Logesh Babu \\ ${ }^{1}$ Department of Optometry, NIMS University Rajasthan, Jaipur. \\ ${ }^{2}$ HOD, Department of Optometry, UIAHS, Chandigarh University, Gharuan, Mohali, India. \\ ${ }^{3}$ Department of Optometry, NIMS University Rajasthan, Jaipur. \\ Corresponding Author: Deepak Gupta
}

DOI: https://doi.org/10.52403/ijhsr.20220218

\begin{abstract}
Introduction: Myopia is the most common visual disorder in school children. This study aims to assess the magnitude of myopia among school children in Faridabad, Haryana, north India.

Methods: In this Cross-sectional study 2370 students were randomly selected. Myopia was defined as the spherical equivalent (SE) refractive error $\geq-0.50 \mathrm{DS}$. Vision check up with Snellen's chart and refractive errors were measured by Retinoscopy and auto refractometer.

Results: Myopia prevalence was found to be $12.36 \%(\mathrm{n}=293)$. The prevalence of myopia was found to be higher among older children 11-14 years (21.30\%). 1294 children of urban and 1076 children of the rural areas were examined. $56.45 \%$ of the study population were boys and $43.54 \%$ were girls. The prevalence of myopia was more in boys (14.27\%) in comparison with girls $(9.88 \%)$. The prevalence of myopia was more in urban area 251(19.39\%) in comparison with rural area 42(3.90\%).

Conclusion: Myopia is a major public health concern and its prevalence is increasing rapidly among school-going children in urban areas. Spectacle is very good option to treat this type of Refractive error.
\end{abstract}

Keywords: Refractive Error; Rural and Urban; School; vision; students; myopia.

\section{INTRODUCTION}

Myopia is one of the major types of refractive errors that can be defined where the light is not able to fall on the retina (in front of Retina) so that the eyes are not able to see distant objects clearly. Myopia is most common cause of defective vision in distance throughout the world. ${ }^{1 .}$

In the Refractive error, Myopia (nearsightedness) is the common cause of blurred vision in distance with an estimated 1.5 billion people affected in 2010 and it is estimated that about half of the world's population will be myopic by $2050 .^{2}$ Prevalence of myopia is more in younger population specially 11-16 year of age varies with geographical locations is higher in urban versus rural populations and is highest among students of high education achievement. . $^{3-5}$

There has, however been no Faridabad study elucidating the prevalence of myopia.

\section{MATERIAL AND METHODS \\ Patient selection and examination}

Our study was a Cross-sectional study, carried out in the 15 randomly selected schools of urban and rural areas Faridabad (Haryana). The students were divided into three age groups: 6-10year, 1114years and 15-16 years, in the Govt. and private schools of the urban and rural field practice area, in each selected school students were randomly chosen. The ethical (EC/2017/14) committee approval was 
taken from Fortis hospital Faridabad to conduct this study.

In all the children, visual acuity was tested with the help of LCD Snellen's chart. If the uncorrected vision was $<6 / 9$ in either, the child was declared to have defective vision. The school were visited by two Optometrist on a plan date. A detailed ocular history was taken about the present and past ocular problems along with the history of the use of spectacles. Visual acuity unaided and aided (if spectacles were being used by the subject \& old power also noted) was recorded using the standard technique for distance and near. The visual status of those children who were already wearing glasses was also assessed for further improvement.

All the students with defective vision were examined by the Optometrist. Objective refraction was performed with Retinoscope (Heine Beta200) and auto refractometer (NIDEK ARK 1) and subjective refraction done until the Normal visual acuity was achieved. For ocular alignment assessment, the Cover test was used for distance $(6 \mathrm{~m})$ and near $(33 \mathrm{~cm})$ with an accommodative fixation target. Ocular motility was checked.

If the student vision is not going to improve 6/9 after correction, then refer to the base hospital (Fortis Hospital Faridabad) for his/her visual acuity, objective Refraction with the help of Retinoscopy and auto refractometer was examine and a complete eye examination was done. Those students already using the glasses also repeat Refraction and change in spectacle power was noted.

Myopia was considered when the measured refraction was more than or equal to $-0.50 \mathrm{D}$ spherical equivalent dioptres in one or both eyes and other retinal problems like; macular scar, ocular trauma, etc. were excluded.

\section{Statistical Analysis}

Analyzed and appropriate statistical tests like simple proportions, chi-Square $\left(\chi^{2}\right)$ / Fisher exact test. The Statistical software SPSS used for the data analysis. Pairwise comparison was assessed using paired t-test for significant value. P-value of less than or equal to 0.05 was considered statistically significant.

\section{RESULT}

After examined 2370 school students, 293 myopic children were identified. The mean age of myopic children was $12.13 \pm 2.61$ years. Among them 251 (85.7\%; - 95\% CI: $81.1 \%-89.5 \%$ ) children belong to urban location and 42 (14.3\%; $95 \%$ CI: $10.5 \%-18.9 \%$ ) belong to rural location (Table 1). The mean age of male myopic children was $12.05 \pm 2.64$ years and of female myopic children was $12.27 \pm 2.56$ years $(\mathrm{p}=0.49$, independent $\mathrm{t}$-test). Gender wise distribution of myopia among myopic children, 105 (35.8\%) children were females and $188(64.2 \%)$ were males.

Table 1: Gender and area wise distribution of myopia

\begin{tabular}{|l|l|l|l|}
\hline & Rural & Urban & Total \\
\hline Female & 26 & 79 & 105 \\
\hline Male & 16 & 172 & 188 \\
\hline Total & 42 & 251 & 293 \\
\hline
\end{tabular}

Chi-square value 14.49, df 1, P-value 0.000

Age-wise distribution of Myopia: An increasing trend was identified for children with myopia. The below table and figure 1 , show the distribution of myopic children among all ages. Chi-square value for trend for this distribution was statistically significant (P-Value 0.006)

Table 2: Age wise distribution of myopia

\begin{tabular}{|c|c|c|c|c|c|}
\hline Age (Years) & Other RE & Myopia & Myopia (\%) & Total & P-Value (Chi-Squared test for trend) \\
\hline 6 & 6 & 10 & $62.5 \%$ & 16 & \multirow{9}{*}{ Chi Square $=7.551 ; \mathrm{P}-$ Value $=0.006$} \\
\hline 7 & 9 & 14 & $60.9 \%$ & 23 & \\
\hline 8 & 12 & 10 & $45.5 \%$ & 22 & \\
\hline 9 & 11 & 17 & $60.7 \%$ & 28 & \\
\hline 10 & 11 & 29 & $72.5 \%$ & 40 & \\
\hline 11 & 8 & 21 & $72.4 \%$ & 29 & \\
\hline 12 & 17 & 48 & $73.8 \%$ & 65 & \\
\hline 13 & 12 & 49 & $80.3 \%$ & 61 & \\
\hline$>14$ & 34 & 95 & $73.6 \%$ & 129 & \\
\hline
\end{tabular}




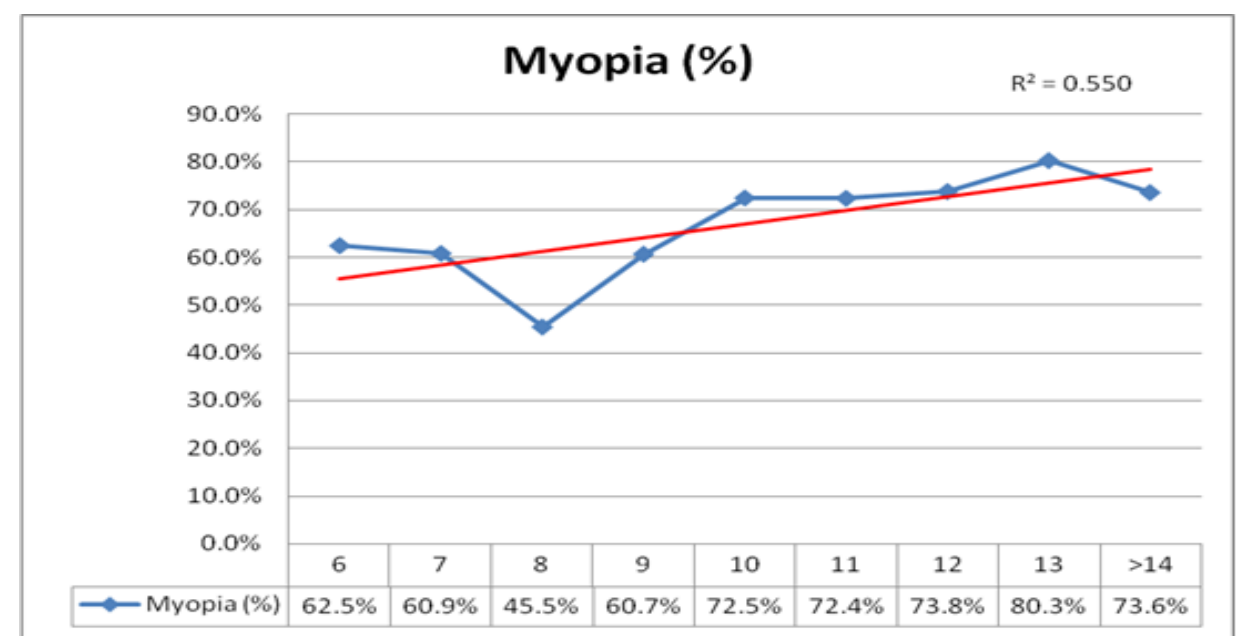

Figure 1. In 293 of all 248 (84.6\%; 95\% CI: 80\%-88.6\%) were mild myopic, 39 were moderate myopic and 6 were high myopic.

Figure 2 Shows that myopia range was most of the students -0.50 to -2.75 (mild myopia indicate by the green bar) than moderate (-3.00D to $-6.0 \mathrm{D})$ and high myopia (>-6.00D) very low indicated by the red dot.

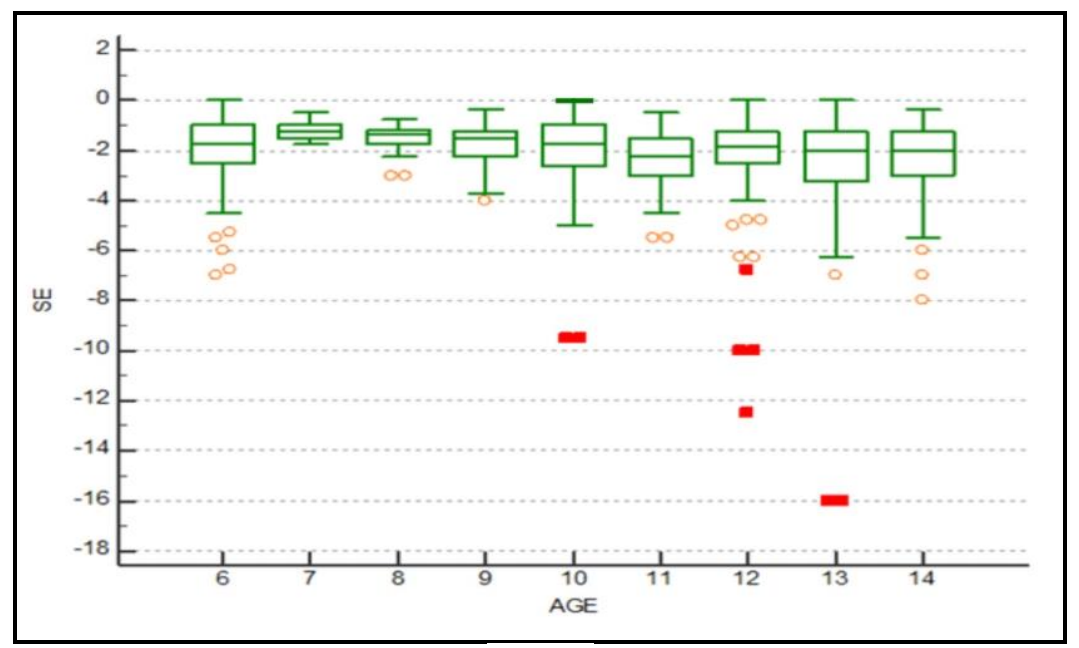

Figure 2.

Table 3: Type of myopia.

\begin{tabular}{|l|l|l|l|}
\hline Mild myopia & Moderate & High Myopia & Total \\
\hline $248(84.64 \%)$ & $39(13.31 \%)$ & $06(2 \%)$ & $293(100 \%)$ \\
\hline
\end{tabular}

Table 4: Age group-wise prevalence of myopia.

\begin{tabular}{|l|l|l|l|}
\hline Age Group & Students & Male & Female \\
\hline $6-10$ & $102(24.69 \%)$ & $62(15.01 \%)$ & $40(9.68 \%)$ \\
\hline $11-14$ & $140(33.89 \%)$ & $88(21.30 \%)$ & $52(12.59 \%)$ \\
\hline $15-16$ & $51(12.34 \%)$ & $38(9.20 \%)$ & $13(3.14 \%)$ \\
\hline Total (N-413) & $293(70.94 \%)$ & $188(45.52 \%)$ & $105(25.42 \%)$ \\
\hline
\end{tabular}

Upper table is showing that the Prevalence of myopia increasing in the middle age group, especially after 11-14 year students. In total myopic 293 students, Myopia affected only one eye in $19(6.5 \%)$ students while both eyes were affected in 274(93.5\%) students (Table 5)

Table 5: Cross Tabulation of Gender vs. Myopia Type

\begin{tabular}{|c|c|c|c|c|}
\hline Gender & Bilateral & Unilateral & Total & \multirow{4}{*}{$\begin{array}{l}\text { P-value } \\
0.24(\text { Pearson Chi-square value }=1.5, \mathrm{df}=1)\end{array}$} \\
\hline Female & 95 & 10 & 105 & \\
\hline Male & 179 & 09 & 188 & \\
\hline Total & $274(93.5 \%)$ & $19(6.5 \%)$ & 293 & \\
\hline
\end{tabular}

\section{DISCUSSION}

The aim of this study was to assess the prevalence of myopia in the rural and urban areas of Faridabad in school-going children. In The Present Study VA <6/9
Was Taken A Defective Vision. Out of Total $(\mathrm{N}=2370), 413$ children $(17.46 \%)$ were found to have defective vision.

In this study, myopia was found in $293(12.36 \%)$ students, in many studies 
myopia is considered when it is >0.50D. This finding is similar to those of S. Seema block of rural of Haryana 2009[7], where $12.1 \%$ prevalence of myopia. This finding was more than Murthy $2002^{8}$, where $7.4 \%$ prevalence of myopia was found in the urban population of Delhi.

It was observed that there was a significant association of increase of myopia (P-0.000) with older age groups especially more than 11 year students.

In our study the prevalence of myopia was lower than Gurugram ${ }^{[9]}$. Where the prevalence of myopia was $21.1 \%$. In West Bengal Durgapur's prevalence of myopia was $23 \%$. It's also higher than our study. Where female $343(13.72 \%)$ were more myopic than male $232(10.88 \%)$ students

It's opposite to our study because male was more myopic in our study but in a rural area, female were more myopic. [10${ }^{11]} 32 \%$ of myopic students were not using the glasses it means we have a need to more aware.

We found a high prevalence of myopia among boys than girls, (7.9\%vs. $4.43 \%$ ). It was almost to finding Gurugram study where myopia among boys than girls (25\% vs. $19 \%$ ).

In all myopia students, 231 students have already eye check-up but 62 were not. In female 83 were already eye checked and 22 were not. In male 148 have already eye checked 40 were not. In all myopia students $199(68 \%)$ were glass user but 94(32\%) were not using the glasses. In which male (124) were more glass users than female (75), maybe some cosmetic and other reasons.

\section{CONCLUSION}

Myopia is major health concern and its prevalence is increasing among school going children in urban area rather than rural area in India. Most of the children are going to spend a lot of time near activity. When students see the clear then perform better. For the myopia control should be seriously considered including reassessments of the current educational system. This cause of vision impairment can be easily treated with Optical correction and high myopia complication can be prevent. So Routine eye examination should be mandatory for school children.

Funding: no any funding given by Govt. and Non Govt.

Limitation: Only school going students were in inclusion criteria and sample size should be more. Age group limitation was 6-16 year.

Further scope: Colour vision also checked and near point of convergence

\section{Acknowledgement}

I am thankful to my guide and coguide. I am greatly thankful to the school teacher, students and parents taking part in this study. I am also thankful to all the staff for their good support.

\section{Conflict of Interest: None}

\section{REFERENCES}

1. Resnikoff S, Pascolini D, Mariotti SP, Pokharel GP. (2008) Global magnitude of visual impairment caused by uncorrected refractive errors in 2004. Bull World Health Organ. Jan; 86(1):63-70. PMID: 18235892.

2. Morgan IG, Ohno-Matsui K, Saw SM. (2012) Myopia. Lancet; 379: 1739-1748. doi: $\quad$ 10.1016/S01406736(12)60272-4 PMID: 22559900.

3. Holden BA, Fricke TR, Wilson DA, et al. Global Prevalence of Myopia and High Myopia and Temporal Trends from 2000 through 2050. Ophthalmology 2016;123: 1036-42.

4. Saw SM, Cheng A, Fong A, et al. School Grades and Myopia. Ophthalmic Physiol Opt 2007; 27:126-9.

5. Tay MT, Au Eong $\mathrm{KG}, \mathrm{Ng} \mathrm{CY}$, et al. Myopia and Educational Attainment in 421,116 Young Singaporean Males. Ann Acad Med Singapore 1992;21: 785-91.

6. Hwang HS, Chun MY, Kim JS, et al. Risk Factors for High Myopia in Koreans: The Korea National Health and Nutrition 
Examination Survey. Curr Eye Res 2018;43: 1052-60.

7. Seema, S., Vashisht, B.M., Meenakshi, K., \& Manish, G. (2009). Magnitude of Refractive Errors among school children in a rural block of Haryana. The Internet Journal of Epidemiology, 6.

8. Murthy GV, Gupta SK, Ellwein LB, Muñoz SR, Pokharel GP, Sanga L, et al. Refractive error in children in an urban population in New Delhi. Invest Ophthalmol Vis Sci 2002; 43:623-631.

9. Singh NK, James RM, Yadav A, Kumar R, Asthana S, Labani S. Prevalence of Myopia and Associated Risk Factors in Schoolchildren in North India. Optom Vis Sci. 2019 Mar;96(3):200-205. doi:
10.1097/OPX.0000000000001344. PMID: 30801501.

10. Atanu Maulik the association between Myopia and near work activities in young adults in Durgapur, West Bengal ": International Journal of Advanced Research, ideas and innovations in technology 2018.

11. Gupta D, Bhatnagar KR, School Eye Survey in Rural and Urban Population in Western India. Indian Journal of Community Ophthalmology. 2020; 1:22-5

How to cite this article: Gupta D, Kumar R, Babu L. Myopia: a school eye survey in rural and urban area of Faridabad, Haryana. Int $J$ Health Sci Res. 2022; 12(2): 132-136. DOI: https://doi.org/10.52403/ijhsr.20220218 